\title{
Highly Sensitive Electrochemical Sensor for Nitrite Based on Polyethyleneimine and Carbon Quantum Dots Composite
}

\author{
Ruizhen Li, ${ }^{1,2 *}$ Lijun Du, ${ }^{1}$ Yu Hu, ${ }^{1}$ Xingyong Liu, ${ }^{3}$ and Guo Liu ${ }^{2,4}$ \\ ${ }^{1}$ School of Chemistry and Environmental Engineering, Sichuan University of Science and Engineering, \\ Zigong 64300, China \\ ${ }^{2}$ State Environmental Protection Key Laboratory of Synergetic Control \\ and Joint Remediation for Soil \& Water Pollution, Chengdu University of Technology, Chengdu 610059, China \\ ${ }^{3}$ School of Chemical Engineering, Sichuan University of Science and Engineering, Zigong 64300, China \\ ${ }^{4}$ State Key Laboratory of Geohazard Prevention and Geoenvironment Protection, \\ Chengdu University of Technology, Chengdu 610059, China
}

(Received August 24, 2021; accepted September 29, 2021)

Keywords: nitrite, electrochemical sensor, carbon quantum dots, polyethyleneimine, nanocomposite

A novel electrochemical sensor for nitrite was fabricated by modifying a glassy carbon electrode (GCE) with a polyethyleneimine and carbon quantum dots (PEI-CQDs) composite. The PEI-CQDs were synthesized by a simple one-pot method. PEI was used not only as a conductive polymer, but also as a nitrogen source to improve the electrocatalytic property and conductivity of CQDs. Moreover, the amino group of PEI can prevent CQDs from aggregating as well as selectively detect nitrite. The physicochemical properties, electrochemical properties, and nitrite sensing performance of these PEI-CQDs were characterized by various techniques. The effects of the $\mathrm{pH}$, mass ratio of nitrogen to carbon sources, and applied potential were studied to find the optimal conditions for nitrite sensing. Under optimized conditions, amperometric and differential pulse voltammetric methods were employed to detect nitrite to obtain the detection range and detection limit, respectively. It was found that the proposed sensor based on PEI-CQDs/GCE exhibited comparable sensing performance to previously reported nitrite sensors with a wide linear range $(0-1000$ and $20-380 \mu \mathrm{M})$ and a low detection limit $(2.87$ and $1.16 \mu \mathrm{M})$. On the basis of the characterization data and the reaction kinetics of nitrite oxidation, a possible mechanism for this sensor is discussed. Moreover, the proposed sensor displayed high selectivity, good reproducibility, and stability under long-term storage and was successfully applied to the detection of nitrite in real samples.

\section{Introduction}

Nitrite is a common toxic inorganic contaminant in nature. It is widely used as a food preservative and meat coloring agent. ${ }^{(1)}$ It has become an indispensable part of food and drink and our daily lives. Moreover, the application of large quantities of nitrogen fertilizer, the burning of fossil fuels, untreated emissions, livestock manure, and organic industrial waste have

*Corresponding author: e-mail: liruizhen007@suse.edu.cn https://doi.org/10.18494/SAM.2021.3597 
exacerbated nitrite accumulation and pollution in the soil, surface water, underground water, and even the physiological system of human bodies worldwide. ${ }^{(2-4)}$ Radioactive waste can also lead to high concentrations of nitrite pollution. ${ }^{(5)}$ Research has shown that once nitrite enters drinking water and the food chain, it can cause a range of serious health issues. For example, nitrite can cause hemoglobin in the body to transform to methemoglobin or can react with hemoglobin irreversibly to form nitro-hemoglobin, which hinders the oxygen transport in cells and causes asphyxia. ${ }^{(6-8)}$ An even more serious problem is that in the presence of various nitrogenous organic compounds (such as amines, phthalein amines, urea, and cyanamide), nitrite can be converted to nitroso compounds with high chemical stability and carcinogenic, teratogenic, and mutagenic properties (for example, nitrosamine and nitrosoamide). These nitroso compounds can lead to the formation of tumors in the intestinal tract, stomach, brain, nervous system, bone, skin, and thyroid. ${ }^{(9,10)}$ In view of the serious harm of nitrite to the environment and human health, the World Health Organization (WHO) stipulates that for short-term exposure, the maximum concentration limit of nitrite is $3 \mathrm{mg} / \mathrm{L}$ in drinking water, and for long-term exposure, it is $0.2 \mathrm{mg} / \mathrm{L} .{ }^{(11)}$

As an unstable intermediate in the environment, nitrite can be easily formed by oxidizing ammonia (or ammonium) or by reducing nitrate under certain conditions. Therefore, a nitrite sample can easily deteriorate in the presence of sufficient oxygen or microbes. The easy convertibility of nitrite makes it difficult to detect, although great progress has been made in the detection of nitrite by various methods including spectrophotometry, ${ }^{(12)}$ chemiluminescence, ${ }^{(13)}$ chromatography, ${ }^{(14)}$ capillary electrophoresis, ${ }^{(15)}$ and spectrofluorimetry. ${ }^{(16)}$ However, almost all these detection methods require sample collection followed by laboratory determination, and it is difficult to establish whether the nitrite sample deteriorated before conducting the laboratory determination. The development of a low-limit and highly sensitive portable in situ monitoring technology for the rapid evaluation of nitrite in a complex environment is urgently required.

Among the various nitrite detection methods, spectrometry has high precision but it is difficult to achieve a detection limit meeting the standard value specified by WHO, and chromatography is time-consuming and costly. In contrast, the electrochemical method has the potential to replace traditional laboratory techniques and for the development of portable and automated in situ monitoring equipment due to its fast response, low cost, simple operation, and high sensitivity. ${ }^{(17)}$ Research based on the use of the electrochemical method for nitrite detection has mainly focused on potentiometry and voltammetry. Compared with spectrometry and chromatography, potentiometry has a wider detection range $(0.2-100 \mathrm{mg} / \mathrm{L})$ and lower detection limit, although some common ions ${ }^{(18)}$ can cause strong interference, whereas the main deficiency of voltammetry is the weak direct electrochemical signal, making it necessary to apply a large bias potential, under which many interfering substances exist. In recent years, considerable effort has been devoted to developing various materials with high electrocatalytic performance and conductivity (such as carbon nanotubes, ${ }^{(19)}$ graphene, ${ }^{(20)}$ carbon nanofibers, ${ }^{(21)}$ and carbon fibers ${ }^{(22)}$ ) as electrode modification materials to construct electrochemical sensors to increase the electron transfer rate and enhance the direct electrochemical signal. Further research is necessary on the use of the electrochemical method for nitrite detection.

Carbon quantum dots (CQDs), a novel zero-dimensional carbon nanomaterial with size less than $10 \mathrm{~nm}$, are potentially useful for many applications, especially in the field of electrochemical 
sensors. Owing to the excellent properties of CQDs, including low toxicity, chemical stability, favorable biocompatibility, simple synthesis with inexpensive raw materials, and the ability to act as both a donor and an acceptor of electrons, ${ }^{(23)}$ they have been successfully and extensively employed in electrochemical sensors. Ramalechume et al. synthesized CQDs doped with a metal oxide and an anionic polymer. A glassy carbon electrode (GCE) of these CQDs modified with this polymer exhibited excellent sensing performance towards lead according to cyclic voltammogram results. ${ }^{(24)}$ Eksin et al. developed CQD-modified disposable pencil graphite electrodes for electrochemical monitoring of the drug-DNA interaction. ${ }^{(25)}$ A hybrid nanocomposite of CQDs $/ \mathrm{Fe}_{3} \mathrm{O}_{4}$ nanoparticles was prepared and applied for the detection of uric acid in human urine samples by Abbas et al. ${ }^{(26)}$ However, the agglomeration ${ }^{(27)}$ and relatively low electrochemical activity ${ }^{(7,28)}$ of CQDs limit their further application. Surface functionalization, ${ }^{(29,30)}$ heteroatom doping, and the formation of composites with other materials with superior properties ${ }^{(31)}$ have been demonstrated to be efficient ways to improve the properties of CQDs.

Various studies have shown that conducting polymers with high conductivity can form composites with carbon materials, greatly improving the conductivity of the carbon materials. The sensitivity and selectivity of sensors based on these composites are also improved. ${ }^{(2,31-35)}$ Motivated by these findings, we have developed a highly sensitive electrochemical sensor for nitrite based on a novel composite composed of a conducting polymer [polyethyleneimine (PEI)] and CQDs (PEI-CQDs) (Scheme 1). In this work, the PEI-CQDs were prepared via a simple onepot method. PEI, a water-soluble cationic polyelectrolyte, was used as a precursor containing the desired $\mathrm{N}$ atom and amino group $\left(-\mathrm{NH}_{2}\right)$ during the synthesis of CQDs. Both $\mathrm{N}$-doping and amino-functionalization of the CQDs were achieved simultaneously. The N-doping improves the

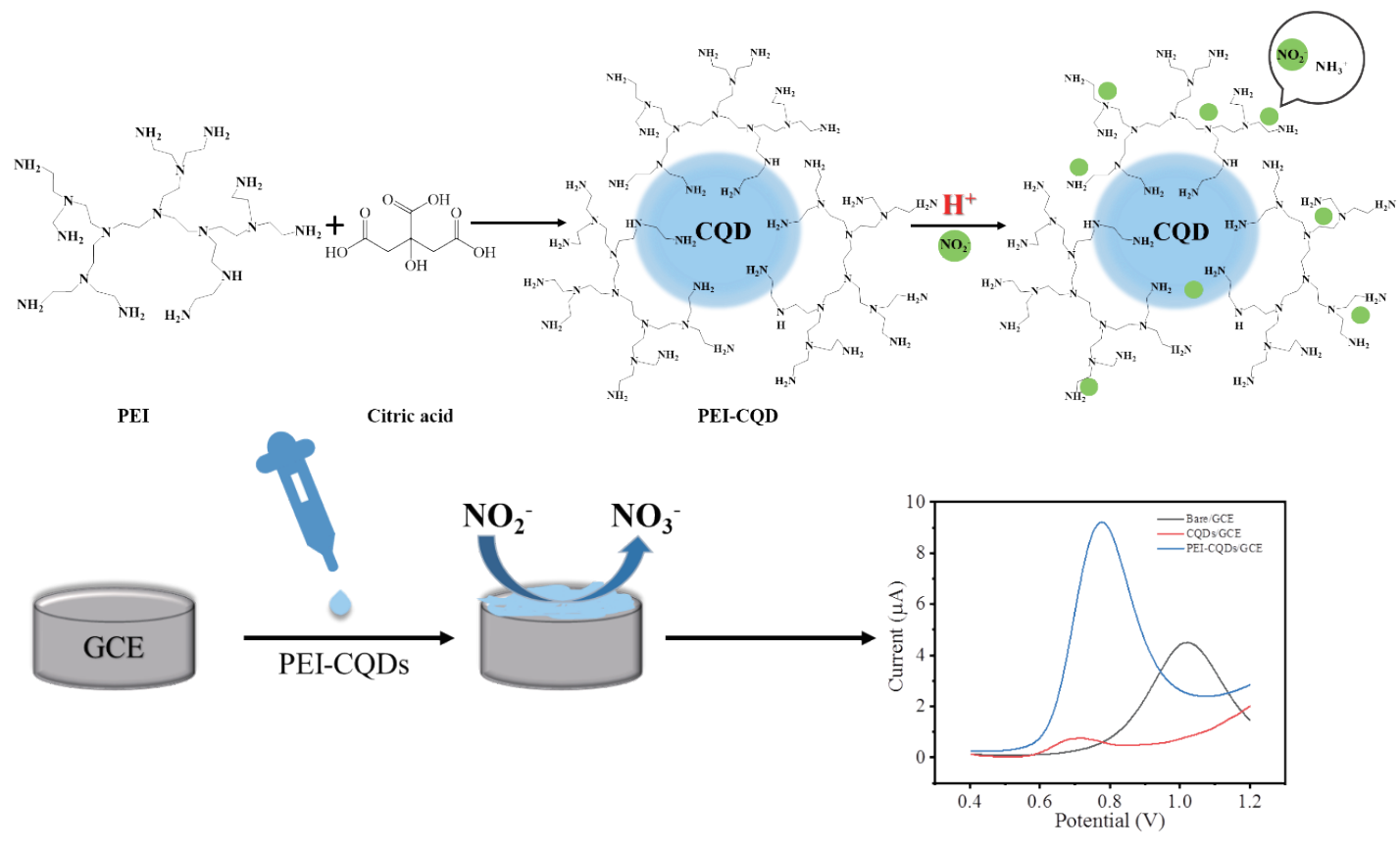

Scheme 1. (Color online) Schematic illustration of synthesis of PEI-CQDs and detection of $\mathrm{NO}_{2}^{-}$. 
electrocatalytic activity of the CQDs and the amino-functionalization increases their electrical conductivity and dispersibility. Moreover, the abundant amino-functional groups on the surface of the as-prepared PEI-CQDs are beneficial for selective detection of the target analyte (nitrite) owing to the interaction between the nitrite and amino groups. The results obtained showed that the proposed electrochemical sensor based on PEI-CQDs exhibited excellent sensing performance towards nitrite.

\section{Experimental methods}

\subsection{Reagents and instrumentation}

As samples for testing, milk and bottled drinking water were purchased from a local supermarket and tap water was collected from the laboratory. Phosphate buffer solution (PBS) of $0.1 \mathrm{M}$ concentration was prepared using $0.1 \mathrm{M} \mathrm{NaH}_{2} \mathrm{PO}_{4}$ and $0.1 \mathrm{M} \mathrm{Na}_{2} \mathrm{HPO}_{4}$, and the $\mathrm{pH}$ was adjusted with $\mathrm{HCl}$ or $\mathrm{NaOH}$ solution. PEI $(\mathrm{Mw}=10000$, 99\%) was obtained from Aladdin Chemistry Co., Ltd. (Shanghai, China). Other reagents of analytical grade were purchased from Adamas Reagent Ltd. (Shanghai, China) and used as received without further purification. Deionized water $(18.2 \mathrm{M} \Omega \mathrm{cm}$ ) was used throughout this work.

High-resolution transmission electron microscopy (HRTEM) images were recorded using an FEI Tecnai G2 F20 S-TWIN field-emission transmission electron microscope (FEI Ltd., USA). Fourier transform infrared (FTIR) spectra were measured with a Nicolet IS10 FTIR spectrometer (Thermo Fisher Scientific, USA). Ultraviolet-visible (UV-vis) absorption spectra were obtained with an L9 double beam UV-vis spectrophotometer (Shanghai INESA Network Co. Ltd., China). All electrochemical measurements were carried out at room temperature $\left(25^{\circ} \mathrm{C}\right)$ with a CHI660E electrochemical workstation (Shanghai Chenhua Instrument Co. Ltd., China). A conventional three-electrode system composed of a platinum sheet auxiliary electrode, a saturated calomel electrode (SCE) reference electrode, and a bare or modified GCE working electrode was used for all electrochemical measurements. All potentials are referenced to the SCE reference electrode. PBS solution of $\mathrm{pH} 6.0$ was used in all electrochemical experiments unless otherwise stated.

\subsection{Synthesis of PEI-CQDs and CQDs}

PEI-CQDs were synthesized by a modified method described previously. ${ }^{(36)}$ Briefly, $200 \mathrm{mg}$ of citric acid and $100 \mathrm{mg}$ of PEI were dispersed in $20 \mathrm{~mL}$ of water. After vigorous stirring for $30 \mathrm{~min}$, the solution was refluxed at $120^{\circ} \mathrm{C}$ for $2 \mathrm{~h}$. The product was naturally cooled to room temperature and then purified with a dialysis tube for $12 \mathrm{~h}$ to remove unreacted reagents. The final solution was stored at $4{ }^{\circ} \mathrm{C}$ until further use. To calculate the concentration of PEICQDs, the PEI-CQDs solution was dried by vacuum freezing and drying technology to acquire the solid. The mass concentration of PEI-CQDs is the ratio of mass to volume. As a control, a material denoted as CQDs was prepared similarly without the addition of PEI. 


\subsection{Fabrication of electrochemical sensor}

Prior to the surface modification, the bare GCE (diameter $=3 \mathrm{~mm}$ ) was carefully polished with 1.0, 0.3, and $0.05 \mu \mathrm{m}$ alumina slurry on the corresponding polishing pad (nylon, nylon, and micro-cloth, respectively). Then the bare GCE was cleaned by ultrasound in deionized water, then in ethanol, and finally in deionized water for $5 \mathrm{~min}$ each, then dried in air. Finally, the pretreated GCE was coated with $5 \mu \mathrm{L}$ of the desired material (PEI-CQDs or CQDs solution) and dried in air at room temperature.

\subsection{Pretreatment of real samples}

To avoid the interference of solid impurities in the samples in the electrochemical measurements of nitrite, each sample was filtered; the milk sample was filtered through a $0.45 \mu \mathrm{m}$ filtering membrane, and the bottled drinking water and tap water were filtered through a $0.22 \mu \mathrm{m}$ filtering membrane. In addition, the filtrate of the milk sample was diluted with $0.1 \mathrm{M}$ PBS solution $(\mathrm{pH}=6.0)$ by a factor of 20 to prepare a stock solution. The pretreated samples were stored at $4{ }^{\circ} \mathrm{C}$ until further use.

\section{Results and Discussion}

\subsection{Characterization of as-prepared PEI-CQDs}

The morphology of the as-prepared PEI-CQDs was observed by transmission electron microscopy (TEM) and HRTEM. As shown in Fig. 1(a), the as-prepared PEI-CQDs have a quasispherical shape and are well dispersed in ethanol. The HRTEM image [Fig. 1(b)] reveals the highly crystalline structure of the PEI-CQDs. According to the corresponding size distribution histogram [Fig. 1(c)], the PEI-CQDs have a size range from 0.15 to $2.85 \mathrm{~nm}$ with a mean value of approximately $1.81 \mathrm{~nm}$, indicating the formation of QDs.

To explore the optical property of the as-prepared PEI-CQDs, the UV-vis absorption spectrum of PEI-CQDs dispersed in aqueous solution was recorded. As illustrated in Fig. 1(d), two clear absorption peaks appeared at 225 and $355 \mathrm{~nm}$, which can respectively be assigned to the $\pi-\pi^{*}$ transition of the $\mathrm{C}=\mathrm{C}$ bond and the $\mathrm{n}-\pi^{*}$ transition of the $\mathrm{C}=\mathrm{O}$ bond of PEI-CQDs. ${ }^{(2,37)}$

An FTIR spectrometer was employed to characterize the surface functional groups of PEICQDs. As displayed in Fig. 1(e), the prominent peak observed at $3430 \mathrm{~cm}^{-1}$ was attributed to stretching vibrations of $\mathrm{N}-\mathrm{H}$ and $\mathrm{O}-\mathrm{H} .{ }^{(38)}$ Two weak peaks appeared at 2980 and $2935 \mathrm{~cm}^{-1}$, corresponding to stretching vibrations of $\mathrm{C}-\mathrm{H} .{ }^{(39,40)}$ The sharp peak at $1630 \mathrm{~cm}^{-1}$ indicated the stretching vibrations of $\mathrm{C}=\mathrm{C}$. ${ }^{(41)} \mathrm{An}$ absorption band at $1450 \mathrm{~cm}^{-1}$ assigned to $\mathrm{N}-\mathrm{H}$ vibration was also visible, demonstrating the presence of the amine functional group on the surface of PEICQDs. ${ }^{(41)}$ Furthermore, the vibrational absorption bands of $\mathrm{C}=\mathrm{O}$ at $1391 \mathrm{~cm}^{-1}{ }^{(42)}$ and $\mathrm{C}-\mathrm{O}$ at $1085^{(38)}$ and $1049 \mathrm{~cm}^{-1}{ }^{(40)}$ were observed. These results not only imply the existence of hydroxyl and carbonyl groups on the surface of the as-prepared PEI-CQDs, indicating the good hydrophilicity of the PEI-CQDs, but also demonstrate their successful amino-functionalization on account of the addition of PEI, which is a rich source of nitrogen. 
(a)

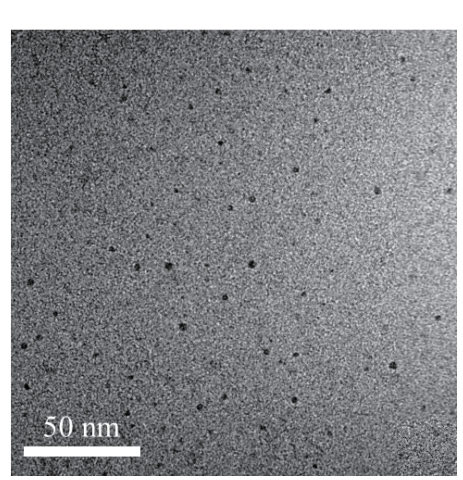

(c)

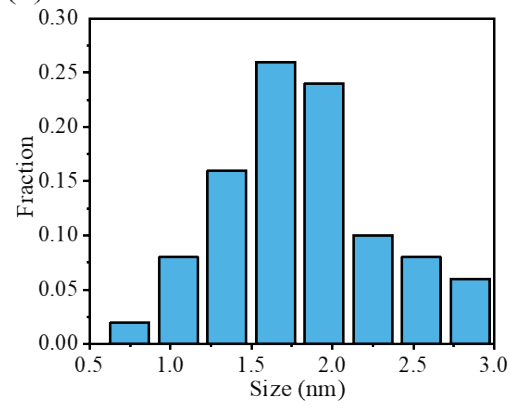

(b)

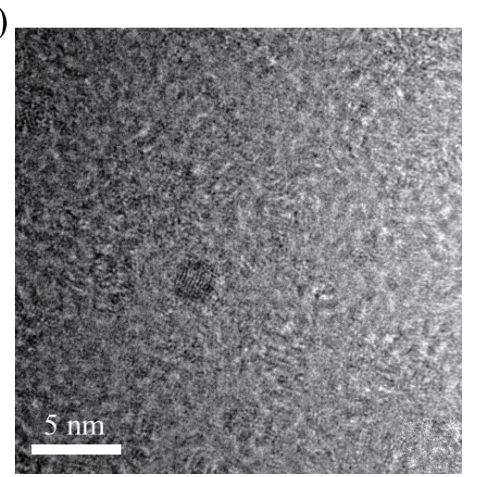

(d)

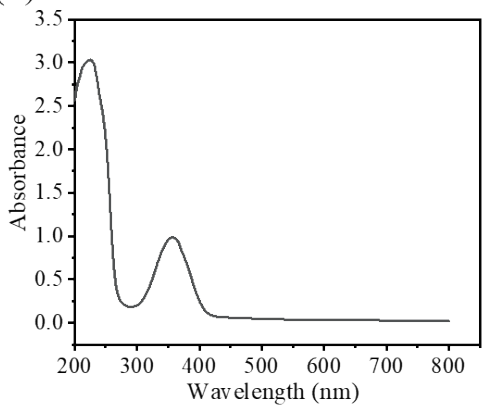

(e)

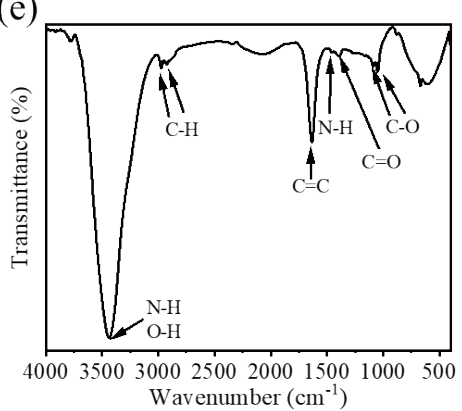

Fig. 1. (Color online) (a) TEM image, (b) HRTEM image, (c) corresponding size distribution histogram, (d) UVvis absorption spectrum, and (e) FTIR spectrum of PEI-CQDs.

X-ray photoelectron spectroscopy (XPS) measurements were carried out to further investigate the chemical composition and nature of the bonding in PEI-CQDs. The PEI-CQDs were clearly composed of $\mathrm{C}, \mathrm{N}$, and $\mathrm{O}$ elements according to the three typical peaks at 285, 400, and $533 \mathrm{eV}$ in the full spectrum [Fig. 2(a)]. According to the high-resolution XPS spectrum, C 1s can be divided into three peaks at 284.2, 285.6, and $287.5 \mathrm{eV}$, as shown in Fig. 2(b), which are ascribed to $\mathrm{C}=\mathrm{C} / \mathrm{C}-\mathrm{C}, \mathrm{C}-\mathrm{OH} / \mathrm{C}-\mathrm{O}-\mathrm{C}$, and $\mathrm{C}=\mathrm{O}$, respectively. ${ }^{(31,39,41,43)}$ Figure 2(c) presents the $\mathrm{O} 1 \mathrm{~s}$ XPS spectrum, in which the peaks located at 530.3 and $531.4 \mathrm{eV}$ were derived from $\mathrm{C}-\mathrm{OH}$ and $\mathrm{C}=\mathrm{O}$, respectively. ${ }^{(41)}$ In addition, peaks corresponding to graphitic nitrogen, ${ }^{(41)}$ surface $\mathrm{NH}_{2}$ groups ${ }^{(44)} /$ amide $\mathrm{N}(\mathrm{C}-\mathrm{N}),{ }^{(45)}$ and doping $\mathrm{N}^{(45)}$ were respectively located at 398.6, 399.6, and $400.8 \mathrm{eV}$ in the high-resolution $\mathrm{N}$ 1s spectrum [Fig. 2(d)], suggesting successful aminofunctionalization and N-doping in the as-prepared PEI-CQDs. The XPS results are highly consistent with the FTIR results. 
(a)

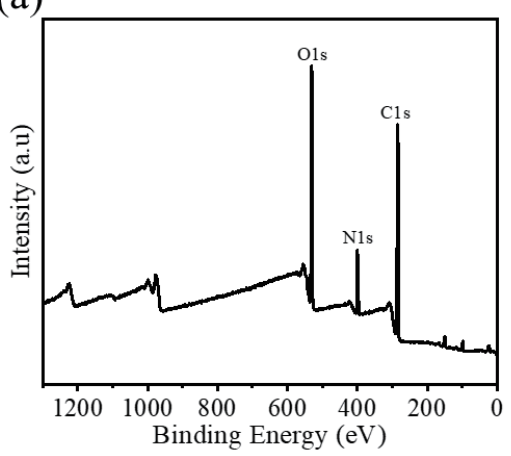

(c)

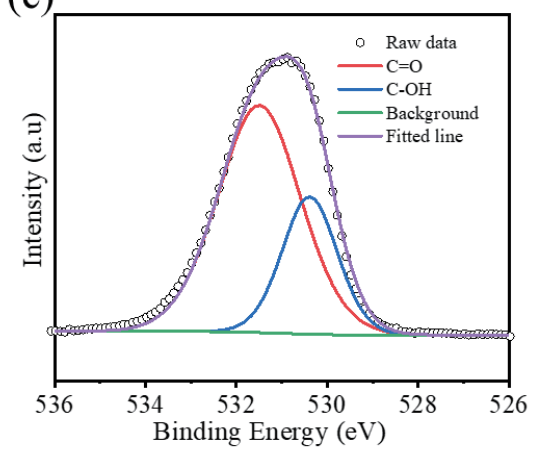

(b)

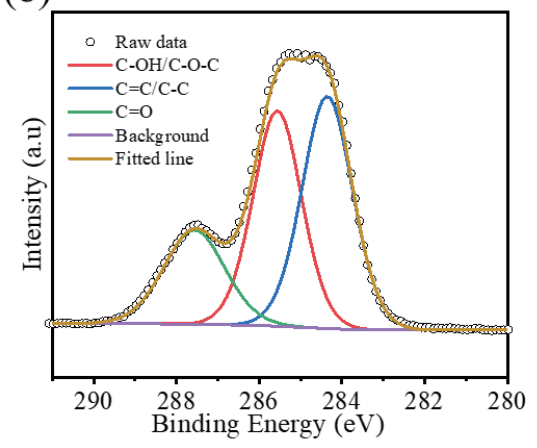

(d)

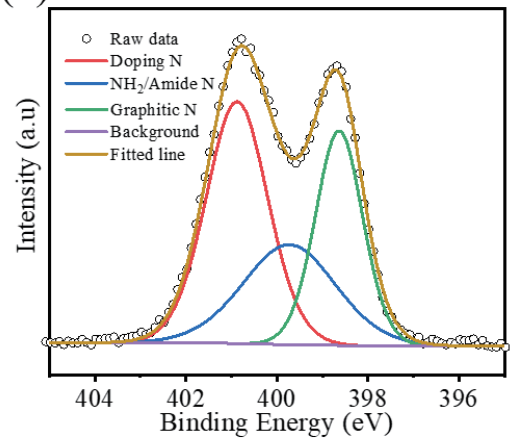

Fig. 2. (Color online) (a) Full-survey XPS spectrum of PEI-CQDs and deconvolution spectra of (b) C 1s, (c) O 1s, and (d) $\mathrm{N} 1 \mathrm{~s}$.

\subsection{Electrochemical characterization}

The electrochemical performances of the bare GCE and different modified GCEs were investigated by cyclic voltammetry (CV) and electrochemical impedance spectroscopy (EIS). As can be seen in Fig. 3(a), a pair of redox peaks of ferricyanide was not observed for the bare GCE under the investigated potential range of 0.8 to $-0.1 \mathrm{~V}$. Moreover, only small redox peaks of ferricyanide were observed for CQDs/GCE, meaning that the GCE was successfully modified by the CQDs. It is believed that electrostatic repulsion occurs between the negatively charged $\mathrm{CQDs}^{(25)}$ and the anion redox probe $\left[\mathrm{Fe}(\mathrm{CN})_{6}\right]^{3-/ 4-}$. Therefore, the decrease in peak current may be contributed to by the inhibition of electron transfer between the CQDs/GCE and the anion redox probe $\left[\mathrm{Fe}(\mathrm{CN})_{6}\right]^{3-/ 4-}$. Nevertheless, a pair of symmetrical and well-behaved redox peaks of ferricyanide with relatively high peak current and small peak separation were observed on PEI-CQDs/GCE, indicating that the introduction of PEI dramatically improves the electrocatalytic activity and electrical conductivity of PEI-CQDs/GCE. These results are consistent with those of EIS analysis. As shown in Fig. 3(b), the diameter of the semicircle in the Nyquist plot representing the interfacial charge-transfer resistance $\left(R_{c t}\right)$ of the GCE electrode was increased after coating with CQDs owing to the electrostatic repulsion. For the PEI-CQDs/ GCE electrode, $R_{c t}$ was much smaller than that for CQDs/GCE, indicating that the introduction of PEI facilitates electron transfer due to the excellent conductivity of the positively charged PEI. 
(a)

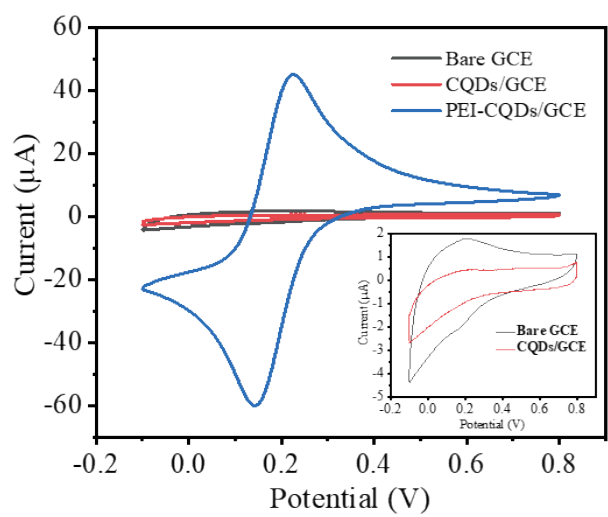

(b)

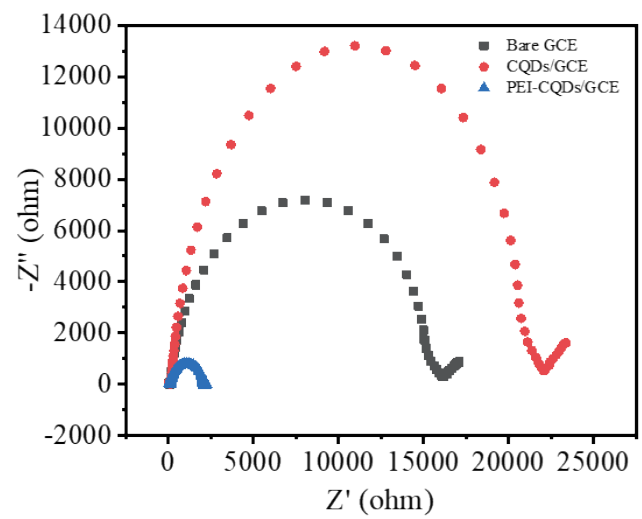

Fig. 3. (Color online) (a) CV curves of bare GCE and different modified GCEs in $5.0 \mathrm{mM}\left[\mathrm{Fe}(\mathrm{CN})^{6}\right]^{3-}$ containing $0.1 \mathrm{M} \mathrm{KCl}$. The inset of (a) shows the CV curves of the bare GCE and CQDs/GCE. (b) Nyquist plots of the bare GCE and different modified GCEs in $5 \mathrm{mM}\left[\mathrm{Fe}(\mathrm{CN})^{6}\right]^{3-/ 4-}$ solution containing $0.1 \mathrm{M} \mathrm{KCl}$ obtained by EIS at room temperature $\left(25^{\circ} \mathrm{C}\right)$.

\subsection{Detection of nitrite on PEI-CQDs/GCE-based electrochemical sensor}

\subsubsection{Electrochemical behavior of nitrite on bare GCE and different modified electrodes}

Figure 4(a) shows the differential pulse voltammetry (DPV) responses of different electrodes to nitrite recorded in $0.1 \mathrm{M}$ PBS solution. A peak assigned to the oxidation of nitrite respectively appeared at $+1.02,+0.708$, and $+0.776 \mathrm{~V}$ on the bare GCE, CQDs/GCE, and PEI-CQDs/GCE. Compared with the bare GCE, the oxidation peak on CQDs/GCE and PEI-CQDs/GCE shifted negatively to a significant extent, demonstrating that the presence of both CQDs and PEI-CQDs decreased the overpotential of nitrite oxidation due to the outstanding electrocatalytic activity of the two materials. In addition, the peak current obtained on PEI-CQDs/GCE was higher than those on the bare GCE and CQDs/GCE, indicating the best sensing performance of the PEICQDs/GCE-based sensor towards nitrite; the peak current obtained on PEI-CQDs/GCE was more than twice that obtained on the bare GCE. The lowest peak current on CQDs/GCE may also be due to the electrostatic repulsion between negatively charged CQDs and nitrite anions that suppressed the transfer of nitrite anions to the surface of the electrode and further inhibited the oxidation of nitrite. These results imply that PEI may act as a conductive polymer and nitrogen source to enhance electron transfer, increase the conductivity, and improve the electrocatalytic activity of CQDs. ${ }^{(7,46)}$ Figure 4(b) shows the DPV response of the PEI-CQDs/ GCE electrode to nitrite at different concentrations. The DPV response increased with increasing concentration of nitrite. Furthermore, the DPV peak current was found to be almost proportional to the nitrite concentration with a correlation coefficient of 0.9995 [see Fig. 4(b), insert], suggesting that PEI-CQDs/GCE is a promising electrochemical sensor to effectively catalyze the oxidation of nitrite and monitor nitrite. 
(a)

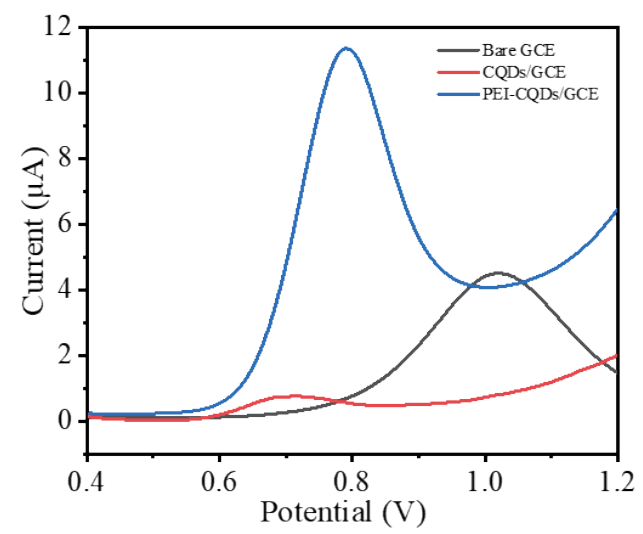

(b)

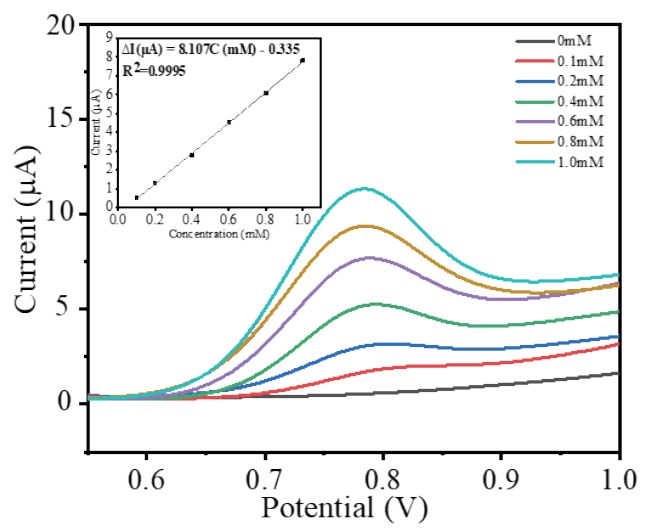

Fig. 4. (Color online) (a) DPV curves of bare GCE, CQDs/GCE, and PEI-CQDs/GCE in 0.1 M PBS containing $1.0 \mathrm{mM} \mathrm{NO}_{2}^{-}$. (b) DPV responses of PEI-CQDs/GCE to different concentrations of nitrite $(0-1 \mathrm{mM})$ in $0.1 \mathrm{M}$ PBS solution. Inset: linear relationship between DPV response of PEI-CQDs/GCE and nitrite concentration at room temperature $\left(25^{\circ} \mathrm{C}\right)$.

\subsubsection{Effects of buffer $\mathrm{pH}$, mass ratio of nitrogen to carbon sources, and applied potential on sensing performance}

To explore the effect of the $\mathrm{pH}$ of the PBS solution on the sensing performance of PEI-CQDs/ GCE towards nitrite, DPV was carried out to detect the response of PEI-CQDs/GCE towards 1 $\mathrm{mM}$ nitrite in $0.1 \mathrm{M}$ PBS with different $\mathrm{pH}$ values. As illustrated in Fig. 5, the $\mathrm{pH}$ of PBS had a significant impact on the sensing performance of PEI-CQDs/GCE towards nitrite. The oxidation peak current increased with increasing $\mathrm{pH}$ from 4.0 to 6.0 , above which the oxidation peak current decreased, indicating that a weak acidic medium is the optimal condition for the oxidation of nitrite. These results can be attributed to two facts. One fact is that the oxidation of nitrite cannot proceed without the participation of hydrogen ions. ${ }^{(37)}$ Therefore, when the $\mathrm{pH}$ was above 6 and the weak acidic condition became neutral and even alkaline, the number of hydrogen ions decreased, the oxidation of nitrite was inhibited, and the peak current decreased. The other fact is that nitrite is not stable in a strongly acidic medium, where it easily undergoes a disproportionation reaction [see Eq. (1)], ${ }^{(47)}$ which affects the electrochemical oxidation of nitrite. Thus, when the $\mathrm{pH}$ was below 6 , the peak current was low. These observations are consistent with the previous literature. ${ }^{(37)}$ Details of this oxidation of nitrite will be discussed later. Thus, a buffer $\mathrm{pH}$ of 6.0, which provided the highest oxidation peak current, was considered as the optimal $\mathrm{pH}$ for nitrite detection.

$$
2 \mathrm{H}^{+}+3 \mathrm{NO}_{2}^{-} \rightarrow 2 \mathrm{NO}+\mathrm{NO}_{3}^{-}+\mathrm{H}_{2} \mathrm{O}
$$

In view of the key role of PEI, the sensor performance is affected by the mass ratio of PEI to citric acid, which respectively act as nitrogen and carbon sources. To acquire PEI-CQDs with 


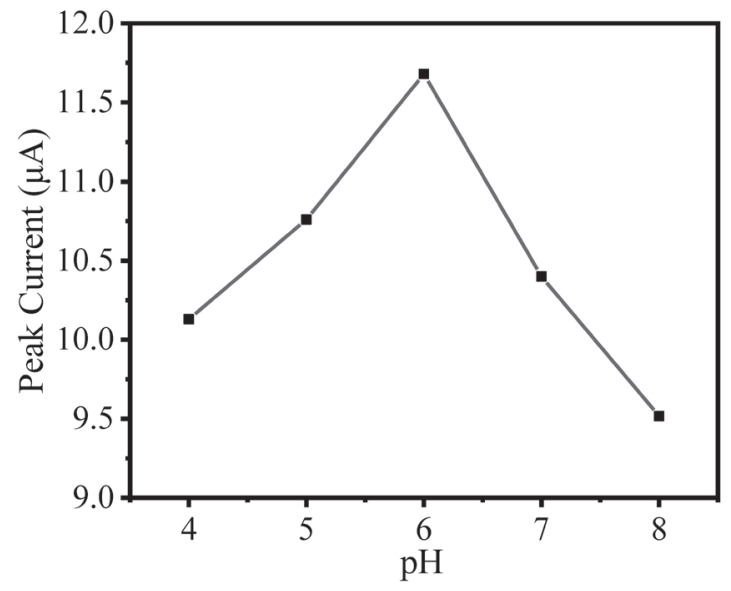

Fig. 5. Effect of $\mathrm{pH}$ of PBS solution on nitrite oxidation peak current for PEI-CQDs/GCE at room temperature (25 ${ }^{\circ} \mathrm{C}$ ). The supporting electrolyte was $0.1 \mathrm{M}$ PBS and the concentration of nitrite was $1 \mathrm{mM}$. The electrochemical measurement method was DPV.

good nitrite detection performance, the experimental conditions were optimized. As the carbon source, the amount of citric acid was fixed to $200 \mathrm{mg}$, and the mass ratio of the nitrogen source to the carbon source was varied by altering the mass of PEI. It was found that the peak current of PEI-CQDs for nitrite increased to a maximum value when the mass ratio of the nitrogen source to the carbon source was increased to 1:2, above which it decreased (see Fig. 6). These results can be attributed to the fact that a moderate amount of PEI, as the nitrogen source and the conducting polymer, will optimize the nitrogen doping, electrocatalytic property, and electrical conductivity of PEI-CQDs, whereas excess PEI will block the passivated nitrogen surface defects. Moreover, considering the excellent dispersibility of PEI, excess PEI may limit the growth of CQDs. Therefore, the optimum mass ratio of PEI to citric acid was 1:2 for the synthesis of PEI-CQDs. Under the optimal conditions, the concentration of synthesized PEI-CQDs was calculated to be $9.93 \mathrm{~g} / \mathrm{L}$.

In addition, the effect of applied potential on the sensing performance of the PEI-CQDs/ GCE-based electrochemical sensor was investigated by recording the typical current-time response curves of PEI-CQDs/GCE towards $1 \mathrm{mM}$ nitrite in $0.1 \mathrm{M}$ PBS. As shown in Fig. 7, the PEI-CQDs/GCE exhibited a sensitive and steady-state current response when the applied potential was set to $+0.7 \mathrm{~V}$, meaning that the electro-oxidation of nitrite had already occurred. Also, the steady-state current increased with increasing applied potential when the potential was less than $+0.8 \mathrm{~V}$. There are two reasons for this result. One is the increased driving force for the fast oxidation of nitrite at a high potential; the other is that the sensor response is controlled by the electrochemical oxidation of nitrite, whose electrochemical oxidation potential is $+0.776 \mathrm{~V}$ [see Fig. 4(a)]. However, when the applied potential is increased to beyond $+0.8 \mathrm{~V}$, the noise signals also increased with the increase in oxidation current. The noise signals were observed to be notable at $+1.0 \mathrm{~V}$. Hence, $+0.8 \mathrm{~V}$ was considered as the optimal applied potential for nitrite determination. 


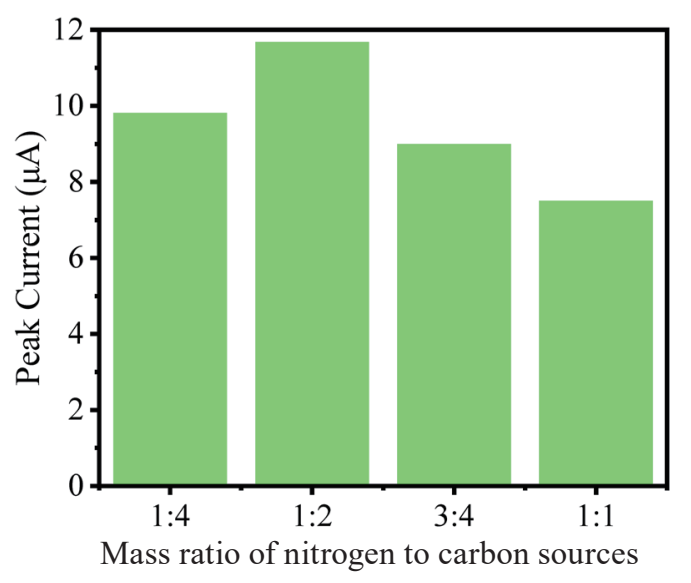

Fig. 6. (Color online) Peak current of PEI-CQDs sensor with different mass ratios of nitrogen source to carbon source for the nitrite obtained. The supporting electrolyte was $0.1 \mathrm{M}$ PBS and the concentration of nitrite was $1 \mathrm{mM}$. The electrochemical measurement method was DPV, which was performed at room temperature $\left(25^{\circ} \mathrm{C}\right)$.

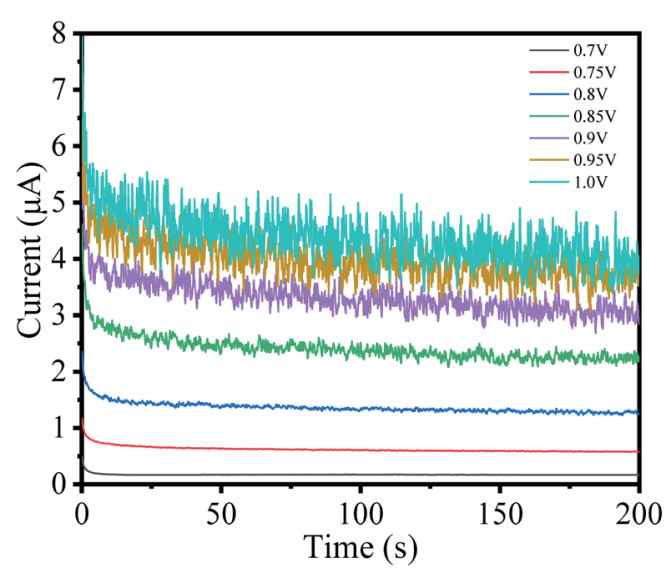

Fig. 7. (Color online) Effect of applied potential on the PEI-CQDs/GCE-based sensor response for $1.0 \mathrm{mM}$ nitrite in $0.1 \mathrm{M}$ PBS solution at room temperature $\left(25^{\circ} \mathrm{C}\right)$.

\subsubsection{Analytical evaluation of sensor performances}

Because of the simplicity and high sensitivity of the amperometric method, it was performed to investigate the electrochemical sensing performance of the sensor towards nitrite under the optimum conditions. The PBS buffer solution was continuously stirred by a magnetic stirring bar during the amperometric experiments to ensure the homogeneity of the solution at every moment after the dropwise addition of nitrite. Figure 8(a) shows the amperometric responses of PEI-CQDs/GCE with the successive addition of nitrite in $0.1 \mathrm{M}$ PBS $(\mathrm{pH}=6.0)$. The applied potential was set as $+0.8 \mathrm{~V}$. After adding an aliquot of nitrite to the buffer solution, the amperometric response current rose sharply to a stable value, demonstrating the fast response of the sensor. The sensor response was evaluated as the difference between the amperometric response current $(\Delta I)$ before and after the addition of nitrite. The sensor response was found to increase linearly with the nitrite concentration in the range of 20 to $380 \mu \mathrm{M}$ with a correlation coefficient of 0.9992 [see Fig. 8(b)]. The linear regression equation can be expressed as $\Delta I(\mu \mathrm{A})$ $=0.0108 \mathrm{C}(\mu \mathrm{M})-1.27$. On the basis of the signal-to-noise ratio of 3 , the limit of detection (LOD) was estimated to be $1.16( \pm) 0.087 \mu \mathrm{M}$. Moreover, when DPV was used for quantitative analysis, the anodic peak current increased almost proportionally with increasing nitrite concentration. The related regression equation defining the straight line, together with the broadened detection range of $0-1 \mathrm{mM}$ and the LOD of 2.87 ( \pm 0.27 ), is shown in Fig. 4(b) and its insert.

Table 1 shows a comparison of the sensing performances of the proposed sensor and previously reported electrochemical sensors. It can be seen that the LOD and detection range of this proposed sensor are comparable to those of the previously reported nitrite sensors fabricated 
(a)

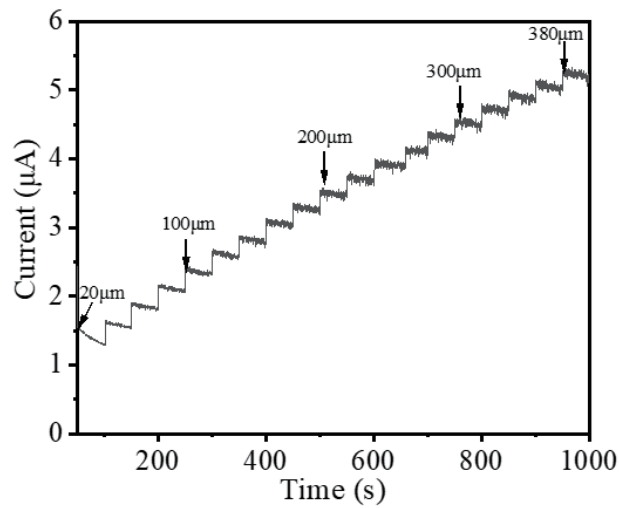

(b)

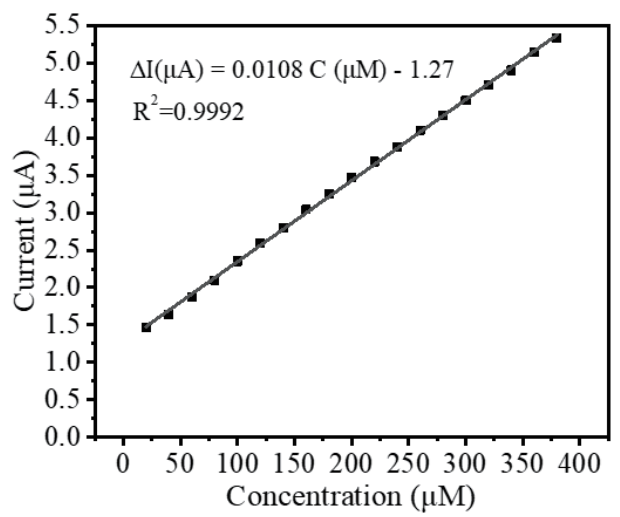

Fig. 8. (a) Amperometric responses of PEI-CQDs/GCE-based sensor with the successive addition of $\mathrm{NaNO}_{2}$ in 0.1 M PBS $(\mathrm{pH}=6.0)$ solution at room temperature $\left(25^{\circ} \mathrm{C}\right)$. The applied potential was set as $+0.8 \mathrm{~V}$. (b) Linear relationship between PEI-CQDs/GCE-based sensor response and nitrite concentration.

Table 1

Comparison of sensing performances of reported electrochemical sensors for nitrite detection.

\begin{tabular}{lcccc}
\hline Modified electrode & Technique & $\begin{array}{c}\text { Linear range } \\
(\mu \mathrm{M})\end{array}$ & $\begin{array}{c}\text { Detection limit } \\
(\mu \mathrm{M})\end{array}$ & Reference \\
\hline CQD PEDOT/GCE & Amperometry & $0.50-1110$ & 0.088 & $(37)$ \\
\hline rGO-MoS 2 -PEDOT/GCE & DPV & $1-1000$ & 0.059 & $(47)$ \\
\hline \multirow{2}{*}{ NGODs@NCNFs/GCE } & DPV & $\begin{array}{c}5-300 \\
400-3000\end{array}$ & 3 & $(7)$ \\
\hline \multirow{2}{*}{ AGCE/ERGO/PBCB/GCE } & Amperometry & $2.49-769$ & 0.48 & \multirow{2}{*}{$(48)$} \\
\cline { 2 - 5 } PolyNiCo/GCE & $\mathrm{CV}$ & $30-500$ & 2.46 & \multirow{2}{*}{$(49)$} \\
\hline \multirow{2}{*}{ PEI-CQDs/GCE } & Amperometry & $2.49-1700$ & 0.45 & \multirow{2}{*}{ This work } \\
\cline { 2 - 5 } & Amperometry & $100-5000$ & 10 & 1.16 \\
\cline { 2 - 5 }
\end{tabular}

with CQDs or a GCE modified with a conductive polymer. Although some sensors exhibited reasonably high sensitivity, the modification of the electrode was complicated and involved time-consuming steps. Moreover, according to the guideline of WHO, the maximum concentration limit of nitrite in drinking water is $65.2 \mu \mathrm{M},{ }^{(31)}$ which is far higher than the LOD of the proposed sensor. Hence, the PEI-CQDs/GCE-based sensor prepared via a simple one-pot method is capable of detecting nitrite effectively.

The CV responses of $1 \mathrm{mM}$ nitrite in $0.1 \mathrm{M}$ PBS $(\mathrm{pH}=6.0)$ on PEI-CQDs/GCE were examined at different scan rates $(v)$ to explore the reaction kinetics of nitrite oxidation. As shown in Fig. 9(a), both the anodic peak current $\left(I_{p a}\right)$ and the peak potential $\left(E_{p a}\right)$ of $\mathrm{NO}_{2}^{-}$at the PEICQDs/GCE increased with increasing scan rate. The corresponding linear relationships of $I_{p a}$ vs $v^{1 / 2}$ and $E_{p a}$ vs $\log v$ are illustrated in Figs. 9(b) and 9(c), respectively. The strongly linear relationship of the former with $R^{2}=0.9996$ indicates that the oxidation of nitrite on PEI-CQDs/ GCE is a diffusion-controlled process. Moreover, the strongly linear relationship of the latter $\left(R^{2}\right.$ $=0.9998)$ implies that the nitrite oxidation is an irreversible electrochemical process. 
(a)

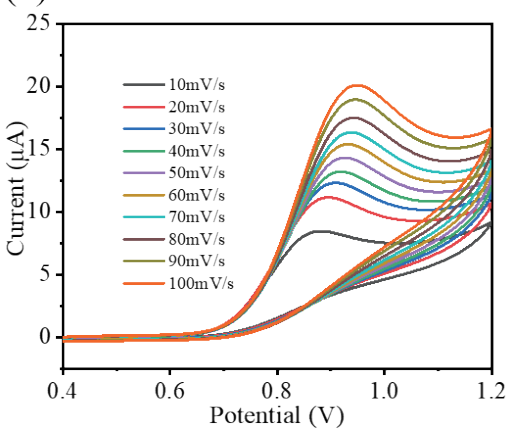

(b)

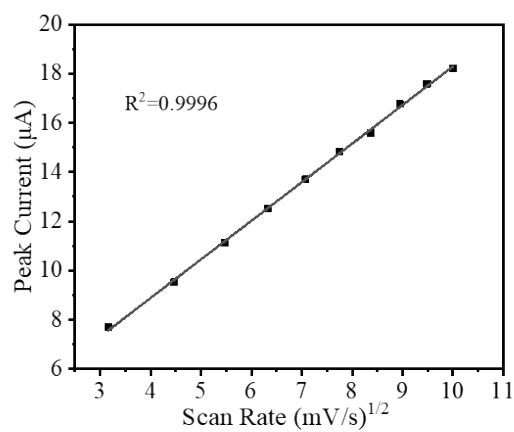

(c)

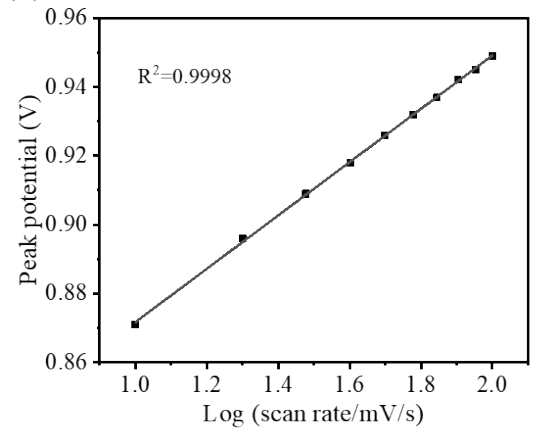

Fig. 9. (Color online) (a) $\mathrm{CV}$ curves of $1.0 \mathrm{mM} \mathrm{NO}_{2}{ }^{-}$in $0.1 \mathrm{M} \mathrm{PBS}(\mathrm{pH}=6.0)$ for PEI-CQDs/GCE at scan rates of $10-100 \mathrm{mV} / \mathrm{s}$. (b) Linear relationship between anodic peak current and square root of scan rate. (c) Linear relationship between anodic peak potential and logarithm of scan rate at room temperature $\left(25^{\circ} \mathrm{C}\right)$.

The overall electrochemical oxidation of nitrite at the surface of PEI-CQDs/GCE can be summarized by the following reactions:

$$
\begin{gathered}
\mathrm{NO}_{2}^{-} \leftrightarrow \mathrm{NO}_{2}+\mathrm{e}^{-}, \\
2 \mathrm{NO}_{2}+\mathrm{H}_{2} \mathrm{O} \rightarrow \mathrm{NO}_{3}^{-}+\mathrm{NO}_{2}^{-}+2 \mathrm{H}^{+}, \\
\mathrm{NO}_{2}^{-}+\mathrm{H}_{2} \mathrm{O} \rightarrow \mathrm{NO}_{3}^{-}+2 \mathrm{H}^{+}+2 \mathrm{e}^{-} .
\end{gathered}
$$

First, the positively charged PEI-CQDs quickly captured negatively charged nitrite ions and accumulated nitrite ions on the electrode surface [Eq. (2)], then the nitrite ions underwent a twoelectron transfer process to complete the irreversible oxidation process [Eqs. (3) and (4)].

A possible mechanism for the electrochemical oxidation of nitrite at the surface of PEICQDs/GCE can be deduced by analyzing the above experimental results. PEI-CQDs/GCE exhibits efficient sensing performance towards nitrite. PEI plays an important role in this sensing system. On one hand, PEI as a nitrogen source improved the electrocatalytic activity of CQDs by introducing $\mathrm{N}$ atoms into CQDs. On the other hand, as a conductive polymer, it improved the conductivity of CQDs. Moreover, during the one-step synthesis process, the 
amino-functionalization of CQDs was also successful by employing PEI as a precursor according to the FTIR and XPS results. The hydrogen bonding between the - $\mathrm{OH}$ group of CQDs and the $-\mathrm{NH}_{2}$ group of $\mathrm{PEI}$ as well as between the $-\mathrm{COOH}$ group of CQDs and the $-\mathrm{NH}_{2}$ group of PEI can ensure the amino-functionalization. In the weak acidic medium, surface amino groups of PEI-CQDs can be protonated and become positively charged, which can capture nitrite through electrostatic interaction and further accelerate the rate-limiting step, namely, the diffusion of nitrite from the electrolyte to the surface of the electrode. Meanwhile, the possible hydrogen bonding between the $\mathrm{O}, \mathrm{H}$, and $\mathrm{N}$ species of $\mathrm{NH}_{3}{ }^{+}$and $\mathrm{NO}_{2}{ }^{-}$may promote the electron transfer in the nitrite oxidation process and realize the selectivity of this sensor towards nitrite.

\subsubsection{Selectivity, stability, and reproducibility}

Selectivity, stability, and reproducibility are three important parameters for evaluating the performance of electrochemical sensors. To assess the selectivity of the as-prepared sensor, various common substances coexistent with nitrite in nature and biological systems [potassium chloride $(\mathrm{KCl})$, calcium chloride $\left(\mathrm{CaCl}_{2}\right)$, magnesium chloride $\left(\mathrm{MgCl}_{2}\right)$, sodium nitrate $\left(\mathrm{Na}_{2} \mathrm{NO}_{3}\right)$, sodium sulfate $\left(\mathrm{Na}_{2} \mathrm{SO}_{4}\right)$, and glucose] were introduced into the sensing system, and the amperometric responses of the PEI-CQDs/GCE sensor with the successive addition of $20 \mu \mathrm{M}$ nitrite and $100 \mu \mathrm{M}$ of the above-mentioned coexistent substances in $0.1 \mathrm{M}$ PBS $(\mathrm{pH}=6.0)$ were tested under optimum conditions. It can be seen from Fig. 10(a) that the coexistent substances did not cause noticeable interference in the amperometric response of the sensor towards nitrite, even when their concentrations were fivefold that of nitrite, indicating the remarkable antiinterference ability of the PEI-CQDs/GCE sensor for detecting nitrite.

In addition, the stability of the PEI-CQDs/GCE sensor was evaluated by monitoring the DPV response of a single PEI-CQDs/GCE sensor towards $1 \mathrm{mM}$ nitrite in $0.1 \mathrm{M} \mathrm{PBS}(\mathrm{pH}=6.0)$ every 10 days. The PEI-CQDs/GCE sensor was stored at $4{ }^{\circ} \mathrm{C}$ unless in use. The stability was estimated from the change in the peak current with the storage time. Figure 10(b) shows the DPV response after $0,10,20$, and 30 days. As shown in Fig. 10(b), $I_{0}$ is the initial peak current and $I_{t}$ is the peak current at time $t$. Although the peak current decreased with increasing storage time, no significant decrease in the peak current was observed in the first 10 days, and the loss was only $15.7 \%$ after 30 days, demonstrating the stability of the proposed sensor under long-term storage.

The reproducibility of a single sensor (intra-assay) and the reproducibility between sensors (inter-assay) were both investigated. To ascertain the intra-assay reproducibility, CV curves of a single PEI-CQDs/GCE sensor were consecutively recorded 50 times in $0.1 \mathrm{M} \mathrm{PBS}(\mathrm{pH}=6.0)$ containing $1 \mathrm{mM}$ nitrite with a scan rate of $50 \mathrm{mV} / \mathrm{s}$. The relative standard deviation (RSD) of the 50 oxidation peak currents was calculated to be $2.05 \%$ [see Fig. 10(c)]. At the same time, the inter-assay reproducibility was evaluated by detecting the DPV response of three independently prepared PEI-CQDs/GCE sensors in $0.1 \mathrm{M}$ PBS $(\mathrm{pH}=6.0)$ containing $1 \mathrm{mM}$ nitrite [see Fig. 10(d)]. The RSD value for the inter-assay was $2.61 \%$. These results confirmed the good reproducibility of the proposed sensor. 
(a)

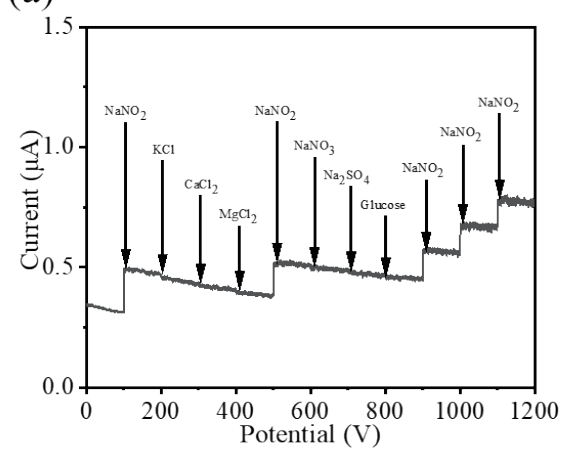

(c)

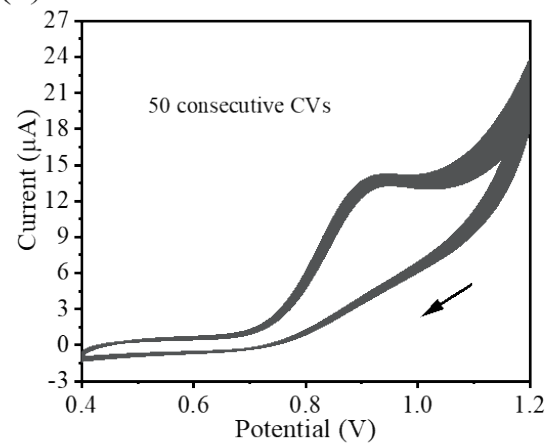

(b)

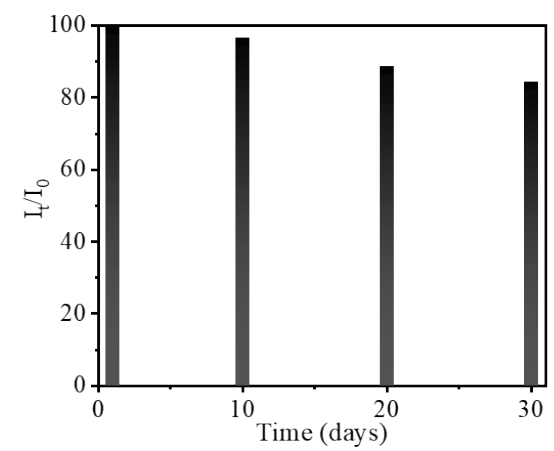

(d)

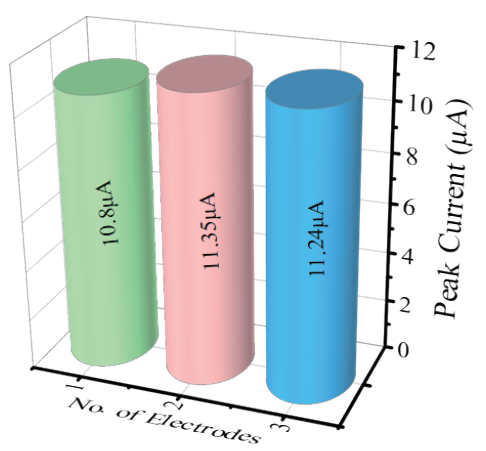

Fig. 10. (Color online) (a) Amperometric response of the PEI-CQDs/GCE sensor with successive addition of $20 \mu \mathrm{M}$ nitrite and $100 \mu \mathrm{M}$ various common coexistent substances in $0.1 \mathrm{M}$ PBS $(\mathrm{pH}=6.0)$ under optimum conditions. (b) Long-term stability of a single PEI-CQDs/GCE sensor for detecting $1 \mathrm{mM}$ nitrite in $0.1 \mathrm{M}$ PBS $(\mathrm{pH}=6.0)$ by employing DPV. (c) Consecutive CVs obtained in reproducibility tests of a single PEI-CQDs/GCE sensor in $0.1 \mathrm{M}$ PBS $(\mathrm{pH}=6.0$ ) containing $1 \mathrm{mM}$ nitrite with a scan rate of $50 \mathrm{mV} / \mathrm{s}$. (d) DPV responses of three independently prepared PEI-CQDs/GCE sensors in $0.1 \mathrm{M} \mathrm{PBS}(\mathrm{pH}=6.0)$ containing $1 \mathrm{mM}$ nitrite at room temperature $\left(25^{\circ} \mathrm{C}\right)$.

\subsubsection{Determination of nitrite in real samples}

The sensor based on PEI-CQDs/GCE was used to determine the nitrite content in real samples of milk, bottled drinking water, and tap water to assess its applicability. Prior to the analysis, the samples were pretreated by the procedure described in Sect. 2. Since nitrite ions were not detected in these real samples by using both this sensor and standard ion chromatography, a standard addition method was employed, namely, the pretreated samples were spiked with a known amount of standard nitrite solution, and the amperometric technique was carried out under the optimal conditions to detect nitrite. To verify the accuracy of the detection results of the proposed sensor, standard ion chromatography was also employed to detect nitrite in these samples. Table 2 shows the analytical results. The recoveries obtained for the milk, bottled drinking water, and tap water by the proposed sensor were $84.81-89.89 \%$, 99.97-100.29\%, and $99.98-100.33 \%$, respectively, which is comparable to the recovery of standard ion chromatography, indicating the reliability of the proposed sensor. Moreover, the good recovery indicates the feasibility of the proposed sensor for nitrite determination in real samples. 
Table 2

Amperometric determination results for nitrite in real samples using standard addition method $(n=3)$.

\begin{tabular}{|c|c|c|c|c|c|}
\hline $\begin{array}{l}\text { Spiked } \\
(\mu \mathrm{M})\end{array}$ & Sample & $\begin{array}{l}\text { Detected by } \\
\text { proposed sensor } \\
(\mu \mathrm{M})\end{array}$ & $\begin{array}{l}\text { Recovery of } \\
\text { proposed sensor } \\
(\%)\end{array}$ & $\begin{array}{l}\text { Detected by ion } \\
\text { chromatography } \\
\qquad(\mu \mathrm{M})\end{array}$ & $\begin{array}{l}\text { Recovery of ion } \\
\text { chromatography } \\
(\%)\end{array}$ \\
\hline 100 & \multirow{2}{*}{ Milk } & 89.89 & 89.89 & 102.59 & 102.59 \\
\hline 300 & & 254.43 & 84.81 & 321.01 & 107 \\
\hline 100 & \multirow{2}{*}{$\begin{array}{l}\text { Bottled drinking } \\
\text { water }\end{array}$} & 100.29 & 100.29 & 86.51 & 86.51 \\
\hline 300 & & 299.90 & 99.97 & 301.15 & 100.38 \\
\hline 100 & \multirow{2}{*}{ Tap water } & 100.33 & 100.33 & 87.7 & 87.7 \\
\hline 300 & & 299.94 & 99.98 & 298.71 & 99.57 \\
\hline
\end{tabular}

\section{Conclusion}

A novel electrochemical sensor based on PEI-CQDs/GCE for nitrite detection was developed by a simple one-step method. The results of TEM, FTIR, and XPS confirmed that the PEI precursor not only introduced $\mathrm{N}$ atoms into PEI-CQDs, but also maintained the dispersibility of the PEI-CQDs and realized their amino-functionalization. The experimental results showed that PEI-CQDs/GCE can be used as a highly sensitive and selective electrochemical sensor for nitrite detection because of its excellent electrocatalytic property and conductivity. Moreover, in a weak acidic medium, the electrostatic interaction and hydrogen bonding between protonated amino groups of PEI-CQDs and nitrite also improved the sensitivity and selectivity of this sensor. Under optimum conditions, the proposed sensor has a wide linear range (0-1000 and 20-380 $\mu \mathrm{M})$ and a low LOD $(2.87$ and $1.16 \mu \mathrm{M})$ and displayed good reproducibility, stability under longterm storage, and high selectivity for nitrite detection. Nitrite in real samples of milk, bottled drinking water, and tap water was successfully determined using the proposed sensor, suggesting its applicability for nitrite detection in food, the environment, and other areas.

\section{Acknowledgments}

This work was supported by the National Natural Science Foundation of China (Grant No. 61601313), the Opening Project Foundation of State Environmental Protection Key Laboratory of Synergetic Control and Joint Remediation for Soil \& Water Pollution (Grant No. GHBK-004), the Municipal Key Science and Technology Project Foundation of Zigong (Grant No. 2020YGJC04) (all for R.L.), and the Scientific Research and Innovation Team Project Foundation of Education Department of Sichuan Province (Grant No.17TD0025) (for X.Y.)

\section{Conflicts of Interest}

The authors declare that there are no conflicts of interest regarding the publication of this paper. 


\section{References}

1 D. Cvetković, V. Živković, V. Lukić, and S. Nikolić: Forensic Sci. Med. Pathol. 15 (2019) 102. http://doi. org/10.1007/s12024-018-0036-1

2 J. Chen, P. He, H. Bai, S. He, T. Zhang, X. Zhang, and F. Dong: Sens. Actuators, B 252 (2017) 9. https://doi. org/10.1016/j.snb.2017.05.096

3 Y. Liu, S. Luo, P. Wu, C. Ma, X. Wu, M. Xu, W. Li, and S. Liu: Anal. Chim. Acta 1090 (2019) 133. https://doi. org/10.1016/j.aca.2019.09.015

4 M. Sivakumar: Int. J. Electrochem. Sci. (2017) 4835. http://doi.org/10.20964/2017.06.24

5 P. Albina, N. Durban, A. Bertron, A. Albrecht, J.-C. Robinet, and B. Erable: J. Environ. Manage. 280 (2021) 111859. https://doi.org/10.1016/j.jenvman.2020.111859

6 Z. Ding, S. D. Johanningsmeier, R. Price, R. Reynolds, V.-D. Truong, S. C. Payton, and F. Breidt: Food Control 90 (2018) 304. https://doi.org/10.1016/j.foodcont.2018.03.005

7 L. Li, D. Liu, K. Wang, H. Mao, and T. You: Sens. Actuators, B 252 (2017) 17. https://doi.org/10.1016/j. snb.2017.05.155

8 C. e. Zou, B. Yang, D. Bin, J. Wang, S. Li, P. Yang, C. Wang, Y. Shiraishi, and Y. Du: J. Colloid Interface Sci. 488 (2017) 135. https://doi.org/10.1016/j.jcis.2016.10.088

9 A. Butler: J. Ethnopharmacol. 167 (2015) 105. https://doi.org/10.1016/j.jep.2014.09.040

10 J. Kobayashi: Nitric Oxide 73 (2018) 66. https://doi.org/10.1016/j.niox.2017.06.001

11 Z. Zhao, J. Zhang, W. Wang, Y. Sun, P. Li, J. Hu, L. Chen, and W. Gong: Appl. Surf. Sci. 485 (2019) 274. https:// doi.org/10.1016/j.apsusc.2019.04.202

12 M. Miró, A. Cladera, J. M. Estela, and V. Cerdà: Analyst 125 (2000) 943. http://doi.org/10.1039/A910263I

13 E. Nagababu and J. Rifkind: Methods Mol. Biol. (Clifton, N.J.) 610 (2010) 41. http://doi.org/10.1007/978-160327-029-8 3

14 H. Kodamatani, S. Yamazaki, K. Saito, T. Tomiyasu, and Y. Komatsu: J. Chromatogr. A 1216 (2009) 3163. https://doi.org/10.1016/j.chroma.2009.01.096

15 N. Öztekin, M. S. Nutku, and F. B. Erim: Food Chem. 76 (2002) 103. https://doi.org/10.1016/S0308$\underline{8146(01) 00287-4}$

16 Q.-H. Liu, X.-L. Yan, J.-C. Guo, D.-H. Wang, L. Li, F.-Y. Yan, and L.-G. Chen: Spectrochim. Acta, Part A 73 (2009) 789. https://doi.org/10.1016/j.saa.2009.03.018

17 Y. Mao, Y. Bao, D.-X. Han, and B. Zhao: Chin. J. Anal. Chem. 46 (2018) 147. https://doi.org/10.1016/S18722040(17)61066-1

18 M. A. P. Mahmud, F. Ejeian, S. Azadi, M. Myers, B. Pejcic, R. Abbassi, A. Razmjou, and M. Asadnia: Chemosphere 259 (2020) 127492. https://doi.org/10.1016/j.chemosphere.2020.127492

19 Q. Sheng, D. Liu, and J. Zheng: J. Electroanal. Chem. 796 (2017) 9. https://doi.org/10.1016/j.jelechem.2017.04.050

20 X. Xie, B. Zhou, Y. Zhang, G. Zhao, and B. Zhao: Chem. Phys. Lett. 767 (2021) 138355. http://dx.doi. org/10.1016/j.cplett.2021.138355

21 S. Yang, M. Yang, X. Yao, H. Fa, Y. Wang, and C. Hou: Sens. Actuators, B 320 (2020) 128294. https://doi. org/10.1016/j.snb.2020.128294

22 Y. Zhang, W. Zhu, Y. Wang, Y. Ma, J. Sun, T. Li, J. Wang, X. Yue, S. Ouyang, and Y. Ji: Inorg. Chem. Front. 6 (2019) 1501. http://doi.org/10.1039/C9QI00255C

23 M. Kováčová, E. Špitalská, Z. Markovic, and Z. Špitálský: Part. Part. Syst. Char. 37 (2020) 1900348. https:// doi.org/10.1002/ppsc. 201900348

24 C. Ramalechume, S. Keerthana, and C. Mercy Andrew Swamidoss: Mater. Today: Proc. (2020). https://doi. org/10.1016/j.matpr.2020.10.693

25 E. Eksin, H. Senturk, E. Zor, H. Bingol, and A. Erdem: J. Electroanal. Chem. 862 (2020) 114011. https://doi. org/10.1016/j.jelechem.2020.114011

26 M. W. Abbas, R. A. Soomro, N. H. Kalwar, M. Zahoor, A. Avci, E. Pehlivan, K. R. Hallam, and M. Willander: Microchem. J. 146 (2019) 517. https://doi.org/10.1016/j.microc.2019.01.034

27 K. Hagiwara, H. Uchida, Y. Suzuki, T. Hayashita, K. Torigoe, T. Kida, and S. Horikoshi: RSC Adv. 10 (2020) 14396. http://doi.org/10.1039/D0RA01349H

28 D. Konstantinos: Curr. Org. Chem. 20 (2016) 682. http://doi.org/10.2174/1385272819666150730220948

29 S. P. Jovanović, Z. Syrgiannis, Z. M. Marković, A. Bonasera, D. P. Kepić, M. D. Budimir, D. D. Milivojević, V. D. Spasojević, M. D. Dramićanin, V. B. Pavlović, and B. M. Todorović Marković: ACS Appl. Mater. Interfaces 7 (2015) 25865. http://doi.org/10.1021/acsami.5b08226

30 M. Kaur, M. Kaur, and V. K. Sharma: Adv. Colloid Interface Sci. 259 (2018) 44. https://doi.org/10.1016/j. cis.2018.07.001 
31 M. Ghanei-Motlagh and M. A. Taher: Biosens. Bioelectron. 109 (2018) 279. https://doi.org/10.1016/j. bios.2018.02.057

32 Y. Chen, W. Wei, Y. Zhu, J. Luo, and X. Liu: Compos. Sci. Technol. 170 (2019) 25. https://doi.org/10.1016/j. compscitech.2018.11.026

33 M. Guo, J. Chen, J. Li, B. Tao, and S. Yao: Analytica Chimica Acta 532 (2005) 71. https://doi.org/10.1016/j. aca.2004.10.045

34 F. Kuralay, M. Dumangöz, and S. Tunç: Talanta 144 (2015) 1133. https://doi.org/10.1016/j.talanta.2015.07.095

35 A. G. Zestos, C. B. Jacobs, E. Trikantzopoulos, A. E. Ross, and B. J. Venton: Anal. Chem. 86 (2014) 8568. http://doi.org/10.1021/ac5003273

36 Z.-H. Chen, X.-Y. Han, Z.-Y. Lin, Y.-L. Fan, G. Shi, S. Zhang, and M. Zhang: Biotechnol. Appl. Biochem. 66 (2019) 426. https://doi.org/10.1002/bab.1739

37 M. Jiao, Z. Li, Y. Li, M. Cui, and X. Luo: Microchimica Acta 185 (2018) 249. http://doi.org/10.1007/s00604018-2784-8

38 L. Wang, W. Li, B. Wu, Z. Li, S. Wang, Y. Liu, D. Pan, and M. Wu: Chem. Eng. J. 300 (2016) 75. https://doi. org/10.1016/j.cej.2016.04.123

39 W. Han, D. Li, M. Zhang, H. Ximin, X. Duan, S. Liu, and S. Wang: J. Hazard. Mater. 395 (2020) 122695. https://doi.org/10.1016/j.jhazmat.2020.122695

40 N. Jamaludin, T. L. Tan, A. A.-O. Zaman, A. R. Sadrolhosseini, and S. A.-O. Rashid: Materials 13 (2020) 3356. https://doi.org/10.3390/ma13153356

41 S. S. Arumugam, J. Xuing, A. Viswadevarayalu, Y. Rong, D. Sabarinathan, S. Ali, A. A. Agyekum, H. Li, and Q. Chen: J. Photochem. Photobiol., A 401 (2020) 112788. https://doi.org/10.1016/j.jphotochem.2020.112788

42 Y. Liu, Y. Zhao, and Y. Zhang: Sens. Actuators, B 196 (2014) 647. https://doi.org/10.1016/j.snb.2014.02.053

43 X. Yue, Z. Zhou, Y. Wu, M. Jie, Y. Li, H. Guo, and Y. Bai: New J. Chem. 44 (2020) 8503. http://doi.org/10.1039/ D0NJ01025A

44 C. Zhang, J. Su, H. Zhu, J. Xiong, X. Liu, D. Li, Y. Chen, and Y. Li: RSC Adv. 7 (2017) 34182. http://doi. org/10.1039/C7RA03056H

45 H. Su, Y. Liao, F. Wu, X. Sun, H. Liu, K. Wang, and X. Zhu: Colloids Surf., B 170 (2018) 194. https://doi. org/10.1016/j.colsurfb.2018.06.014

46 Z. Ye, Y. Zhang, G. Li, and B. Li: Anal. Lett. 53 (2020) 2841. http://doi.org/10.1080/00032719.2020.1759618

47 R. Madhuvilakku, S. Alagar, R. Mariappan, and S. Piraman: Anal. Chim. Acta 1093 (2020) 93. https://doi. org/10.1016/j.aca.2019.09.043

48 A. J. S. Ahammad, M. K. Alam, T. Islam, M. M. Hasan, R. Karim, A. N. Anju, and M. N. I. Mozumder: Electrochim. Acta 349 (2020) 136375. https://doi.org/10.1016/j.electacta.2020.136375

49 T. Islam, M. M. Hasan, S. S. Akter, N. H. Alharthi, M. R. Karim, M. A. Aziz, M. D. Hossain, and A. J. S. Ahammad: ACS Appl. Polym. Mater. 2 (2020) 273. http://doi.org/10.1021/acsapm.9b00797 